\title{
Application of Mathematical Methods for Analysis of Digital ECG Data
}

\section{G. Georgieva-Tsaneva}

Key Words: Electrocardiogram (ECG); HeartRate Variability (HRV); wavelet analysis; Detrended Fluctuation Analysis (DFA); poincare plot .

Abstract. This paper presents several mathematical methods for analysis of electrocardiogram digital data. The measurement of beat to beat fluctuations known as Heart Rate Variability becomes a non-invasive diagnostic technique to study the cardiac autonomic regulation. The analysis was done by software developed by the author. The article presents the results of linear methods, nonlinear methods and wavelet analysis of Heart Rate Variability data in healthy and diseased subjects. The obtained results and the performed comparative analysis demonstrate the possibility for effective application of the considered methods in new cardiovascular information systems.

\section{Introduction}

Cardiovascular morbidity, disability and mortality of them continue to grow globally despite significant progress in the prevention and treatment of these diseases in recent years. Electrocardiography is one of the leading medical non-invasive methods for investigating the cardiovascular system of the human body. For this reason, the clinical electrocardiography is an important part of cardiac studies.

The change in the time interval between cardiac pulsation (beat-to-beat interval) is dynamic, nonlinear, nonstationary and it is defined in the scientific literature as " $R R$ variability" (where $\mathrm{R}$ is a point corresponding to the peak of the ECG wave) or Heart Rate Variability.

Heart Rate Variability is the quantitative expression of the sinus arrhythmia. Sinus arrhythmia refers to the normal increase in heart rate that occurs during inspiration. In the scientific literature, the high variability of the heart rate is considered an indicator of good health, and low variability is a powerful and independent indicator of poor general health. Reduced heart rate variability is unfavorable prognostic sign after myocardial infarction (heart attacks) [1]. In 1996, the European Society of Cardiology and North American Society of Pacing and Electrophysiology supported a Task Force which provided recommendation on clinical usages of the HRV for the evaluation of the risk for cardiology disease and provided initial normative values of standard measures of HRV [2].

The ECG data according to their duration is divided into:

- Short-term (5 to 30 minutes) - they are made with special ECG devices;

- Long-term (up to 24, 48 or 72 hours) - they are made with specialized Holter devices.

Research studies in recent years show that cardiovascular disease can be reduced through early detection, prognosis and prevention.

The aim of this paper is to present the results of linear, non-linear and wavelet analysis of heart rate variability in a group of patients diagnosed with myocardial infarction, a group of patients diagnosed with syncope and healthy control group. In the work is analyzed the ability of described methods to distinguish diseased patients from healthy subjects.

\section{Subjects}

This study is based on the information ECG database of Holter's records obtained from Multiprofile Hospital for Active Treatment "National Cardiac Hospital", Sofia, Bulgaria. The studied Holter database contains over 200 longterm ( 24 hour) records and accompanied by a set common diagnosis by the doctors. The ECG data records are of patients (men and women) with varying degrees of cardiac morbidity in the age range 18-90 years, among them there are records of healthy people. For the purposes of the present study from the information database are separated three groups of subjects: one group consisted of 19 patients diagnosed with myocardial infarction, a group of 17 patients diagnosed with syncope and a control group consisted of 5 healthy subjects. The investigated patients are 19 men and 17 women aged 64 to 87 years. The obtained parameters are presented as mean \pm standard deviation.

\section{Heart Rate Variability}

The research studies show [3-6] that the frequency (table 1) obtained by spectral analysis of the sequence of cardiac intervals reflect normal state of health of the individual.

In the five-minute segment of cardiology data records the main spectral components that are measured are: very low frequencies (Very Low Frequency-VLF), low frequency (Low Frequency-LF) and high frequency (High FrequencyHF) $[2,7]$. Each of these different frequency ranges correspond to certain physiological reasons [8]. Important to determine the general condition of the individual is frequency allocations in two of these ranges: low-frequency and high-frequency, and their attitude (reflecting the interaction between the sympathetic and parasympathetic nervous system) [9]. 


\section{Linear Methods for Analysis of Heart Rate Variability}

Analysis in the time domain. There are several methods by which can be designated variations in the heart rate. Among these, the most simple from the viewpoint of calculation procedures are the methods for analysis in the time domain. Currently analysis of HRV by time domain methods are often practiced. These methods determined the heart rate at any time and calculated the intervals between successive normal complexes (NN (normal-to-normal) time series - intervals between two $\mathrm{R}$ waves belonging to normal heartbeats) [2].

The time domain analysis provides averages of variations for different periods of time. The methods and algorithms of HRV in the time domain are divided into statistical and geometrical. Geometric methods are more complex and have the final result graphs, which are not suitable for subsequent computer processing. The statistical time methods make it possible to calculate the indexes beyond the length of the direct beat-to-beat intervals. These indices are
Table 1. Frequency bands and corresponding frequencies

\begin{tabular}{|l|c|l|}
\hline Frequency range & Frequency $(\mathrm{Hz})$ & \multicolumn{1}{|c|}{ Description } \\
\hline Total power, $m s^{2}$ & $0-0.4$ & $\begin{array}{l}\text { The variance of all normal } \\
\text { intervals. Reflects all cyclic } \\
\text { components of HRV }\end{array}$ \\
\hline $\begin{array}{l}\text { Power in the ultra } \\
\text { low frequency } \\
\text { range (ULF), } m s^{2}\end{array}$ & $0-0.003$ & $\begin{array}{l}\text { Reflects the influence of the } \\
\text { day / night cycle }\end{array}$ \\
\hline $\begin{array}{l}\text { Power in very } \\
\text { low frequency } \\
\text { range (VLF), } m s^{2}\end{array}$ & $0.003-0.04$ & $\begin{array}{l}\text { Reflects the sympathetic } \\
\text { activity of the nervous } \\
\text { system }\end{array}$ \\
\hline $\begin{array}{l}\text { Power in low } \\
\text { frequency range } \\
\text { (LF), } m s^{2}\end{array}$ & $0.04-0.15$ & $\begin{array}{l}\text { Reflects the sympathetic } \\
\text { and parasympathetic activity } \\
\text { of the nervous system }\end{array}$ \\
\hline $\begin{array}{l}\text { Power in high } \\
\text { frequency range } \\
\text { (HF), } m s^{2}\end{array}$ & $0.15-0.4$ & $\begin{array}{l}\text { Reflects the respiratory and } \\
\text { parasympathetic activity of } \\
\text { the nervous system }\end{array}$ \\
\hline LF/HF ratio & - & $\begin{array}{l}\text { This determines the balance } \\
\text { between the sympathetic } \\
\text { and parasympathetic } \\
\text { systems }\end{array}$ \\
\hline
\end{tabular}

used in clinical practice and have gained high credibility. The variables of time domain measures of Heart Rate Variability used in this study are given in table 2 .

Table 2. Statistical and geometrical parameters in the time domain $[2,10]$

\begin{tabular}{|c|c|c|c|c|}
\hline Variable & Units & Description & Formula & Relevance \\
\hline SDNN & $\mathrm{ms}$ & $\begin{array}{l}\text { Standard deviation of the NN } \\
\text { intervals. }\end{array}$ & $\begin{aligned} S D N N & =\sqrt{\frac{1}{N} \sum_{i=1}^{N}\left(R R_{i}-\overline{R R}\right)} \\
\overline{R R} & =\frac{1}{N} \sum_{i=i}^{N} R R_{i}\end{aligned}$ & $\begin{array}{l}\text { Estimate of overall HRV. } \\
\text { Reflects all the cyclic } \\
\text { components responsible for } \\
\text { variability in the period of the } \\
\text { recording. } \\
\text { A decrease in SDNN has } \\
\text { been associated with sudden } \\
\text { cardiac death. }\end{array}$ \\
\hline SDANN & $\mathrm{ms}$ & $\begin{array}{l}\text { Standard deviation of the } \\
\text { averages } \\
\text { calculated over } 5 \text { min periods. }\end{array}$ & $\begin{array}{l}S D A N N=\sqrt{\frac{1}{N} \sum_{i=1}^{N}\left(\overline{R R_{i}}-\overline{\overline{R R}}\right)^{2}} \\
\overline{R R_{i}}-\text { mean of } \mathrm{RR} \text { intervals in } 5 \mathrm{~min} \\
\text { segment, } \\
\overline{\overline{R R}}=\frac{1}{M} \sum_{i=1}^{n} R R_{i}\end{array}$ & $\begin{array}{l}\text { Reflects circadian rhythmicity } \\
\text { of autonomic } \\
\text { function. }\end{array}$ \\
\hline RMSSD & $\mathrm{ms}$ & $\begin{array}{l}\text { The square root of the mean of } \\
\text { the sum of the squares of } \\
\text { successive differences between } \\
\text { adjacent normal intervals. }\end{array}$ & $R M S S D=\sqrt{\frac{1}{N-1} \sum_{i=1}^{N-1}\left(R R_{i+1}-R R_{i}\right)^{2}}$ & $\begin{array}{l}\text { Estimate of the short-term } \\
\text { components of HRV. } \\
\text { Provides Vagal Index. }\end{array}$ \\
\hline $\begin{array}{l}\text { SDNN } \\
\text { index }\end{array}$ & $\mathrm{ms}$ & $\begin{array}{l}\text { Mean of the standard deviations } \\
\text { of all normal intervals for all } 5 \\
\text { min segments of the entire } \\
\text { recording. }\end{array}$ & $S D N N_{\text {index }}=\frac{1}{N} \sum_{i=1}^{N} S D N N_{i}$ & \\
\hline \multicolumn{5}{|c|}{ Geometric measures } \\
\hline
\end{tabular}


Analysis in the frequency domain. The spectral parameters in the frequency domain are calculated for 5 minute segment of the data in these frequency ranges [2]:

- Very Low Frequency-VLF: from $0.003 \mathrm{~Hz}$ to $0.04 \mathrm{~Hz}$;

- Low Frequency-LF: from $0.04 \mathrm{~Hz}$ to $0.15 \mathrm{~Hz}$;

- High Frequency-HF: from $0.15 \mathrm{~Hz}$ to $0.4 \mathrm{~Hz}$.

In this study to determine the spectral parameters is used method of Welch, which is a modification of the traditional Periodogram and is the most popular method of spectral analysis. Heart sampled series of normal intervals is divided into L number of overlapping segments (windows) in order to reduce the high dispersion of Periodogram.

Data located at the end of the time series, receive a smaller weighting factor than the data located in the center. If it is assumed that each segment has $\mathrm{M}$ elements, the modified Periodogram for the segment is given by [11]: where:

(1) $P_{\text {Mod, } x}(f)=\frac{1}{M . U}\left|\sum_{n=0}^{M-1} x_{i}(n) w(n) e^{-j 2 \pi f n}\right|^{2}$

$n=0,1,2,3, \ldots, M-1$,

$i=0,1,2,3, \ldots, L-1$,

$x_{i}(n)=x(n+i D)-i^{\text {th }}$ data segment,

$i D$ - offset $i^{\text {th }}$ data segment.

$U$ is the normalization factor for the power spectrum in the window function $\mathrm{w}(\mathrm{t})$ and is given using [11]:

(2) $U=\frac{1}{M} \cdot \sum_{n=0}^{M-1} w^{2}(n)$.

The modified Periodogram of Welch applies to all segments and calculates the average spectral density of the segments [12]:

(3) $P_{\text {Welch }}(f)=\frac{1}{L} \sum_{i=0}^{L-1} P_{M o d, i}(f)$, where $P_{\text {Mod, } i}(f)$, is the modified Periodogram for the $i^{\text {th }}$ segment of the time series. The obtained Periodogram is:

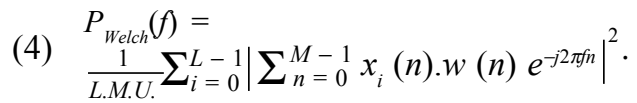

The program implementation uses spline interpolation and calculates the modified Welch Periodogram using a Hamming window.

The spectral parameters give the values of the spectrum in absolute units $\left(m s^{2}\right)$, in percentage and in normal units for the three frequency bands: VLF, LF and HF. It was estimated the relationship LF / HF, which is an indicator of the balance between the sympathetic and parasympathetic nervous system.

\section{Nonlinear Methods for Analysis of Heart Rate Variability}

DFA method for analysis of Heart Rate Variability. Fluctuation analysis to reduce the trend (Detrended fluctuation analysis - DFA) is proposed by Peng (1994) and is an extension of normal fluctuation analysis (Fluctuation Analysis - FA), including analysis of non-stationary processes. The DFA is a technique for detecting correlations in time series. The resulting analysis parameter a is similar to the Hurst exponent and successfully applied to signals, whose statistical or dynamic characteristics are non-stationary. This method is suitable for estimating the fractal properties of short-term series of RR data [4]. HRV is analyzed by the parameter $\alpha$, depending on the slope of the regression line, giving the dependence $\log (F(n))$ of $\log (n)$, where $n$ is the length of the studied time series. The original RR time series (with total length $\mathrm{N}$ ) or its individual segments, first is integrated by calculating the sum of the difference between $i^{\text {th }}$ interval and average of intervals using [13]:

where

$$
\text { (5) } Y(k)=\sum_{i=1}^{k}\left(R R(i)-R_{\mu}\right)
$$

$R R(i)$ - the $i^{\text {th }} \mathrm{RR}$ interval;

$Y(k)$ - the $k^{\text {th }}$ value of integrated series;

$k=1,2, \ldots . . N$;

$R_{\mu}=\overline{R R}=\frac{1}{k} \sum_{j=1}^{k} \overline{R R}(j) \quad-$ the average of $R R(i)$ over the entire series.

The resulting integrated series $Y(k)$ is divided into boxes of equal length $n$, and successively in each box a local trend (labeled $Y n(k)$ ) is subtracted from the data. Thus, the nonstationarity was reduced in integrated series - removing the local linear trend segment by segment. The root-mean square fluctuation $\mathrm{F}(\mathrm{n})$ of this resulting integrated and detrended time series is calculated by the formula [13]:

(6) $F(n)=\sqrt{\frac{1}{N} \sum_{k=2}^{N}\left(Y(k)-Y_{n}(k)\right)^{2}}$.

This procedure is repeated for different lengths of the boxes or for different time scales in order to obtain the relationship between the averaged fluctuation $F(n)$ and boxes length $n$. The DFA shows (in case of RR intervals) typically different correlation properties for small blocks $(n<16)$, and for larger blocks $(n>16)$ [14]. That phenomenon can clearly be seen in the log-log graph of fluctuation $F(n)$. For this reason, in recent years researchers identify two separate scaling exponents, $\alpha_{1}$ and $\alpha_{2}$ - for small and large boxes - reflecting the short-term and long-term fluctuations in the RR time series.

The relationship on a log-log graph between fluctuations $F(n)$ and the time scales $n$ can be estimated by a linear model: $F(n) \sim n^{\alpha}$.

The slope of the regression line between $\log (F(n))$ and $\log (n)$ give the self-similarity parameter, characterized the correlation properties of time series:

$$
\alpha=\frac{\log _{10} F(n)}{\log _{10} n} .
$$

For uncorrelated time series, the value of this fractal parameter is within the range $(0,0.5)$. Values greater than 0.5 $(0.5<\alpha<1.5)$ indicates the presence of correlation in the time series. When $\alpha=1.5$ signal have a high correlation Brownian noise. When $\alpha=1$, signal is a pink noise.

The steps of the algorithm of the DFA are as follows:

1. Determination of integrated RR sequence with length $\mathrm{N}$ using formula (5).

2. Separation of integrated RR sequence to non-overlapping segments (boxes) of equal length $\mathrm{n}$.

3. Calculation of a local linear trend for each segment 
and its removal segment by segment.

4. Averaging all segments and obtaining the fluctuation function according to formula (6).

5. Plotting double-log graph between $F(n)$ and time scales $n$.

6. Determination of the slope of the regression line by least squares.

7. Determination of the fractal parameter $\alpha$.

The Poincarŭ plot method for analysis of Heart Rate Variability. The Poincarŭ plot analysis [15] is a non-linear geometrical method to assess the dynamics of HRV. The Poincarй plot is representation of the time series into a phase space, a scattergram, which is constructed by plotting each cardiac interval (along the $\mathrm{x}$ axis) against the next regular interval (on the $y$-axis). When the heart rate is regular, the points are located on the line of identity $(x=y)$. The standard deviation SD1 is perpendicular to the line of identity and measured short-term variability in heart rate. The standard deviation SD2 is against the line of identity and measured long-term Heart Rate Variability.

\section{Wavelet Transform Analysis of Heart Rate Variability}

Today's most common spectral analysis technique is the Fourier transform or fast Fourier transform, which assumes that the time series is stationary in time [10]. The problem in the use of Fourier transform is lack of temporal resolution and the exact time instant of Heart Rate Variability changes remain unknown. The wavelet analysis maintains time and frequency localization in a time series analysis by decomposing or transforming a one-dimensional time series into a two-dimensional time-frequency data, simultaneously. For this reason the wavelet analysis is applied to analyze nonstationary and non-periodic RR time series. The wavelet transform allows the use of long time intervals to observe more exactly information in low frequency range, and shorter intervals to observe information in high frequency range. The wavelet transform is based on the concept of Multi-Resolution Analysis (MRA). MRA considers the information at different resolutions or scales and represent this information as a collection of details and approximation components. Details are low scale (high frequency) components of signal, while approximations are high scale (low frequency).

For a given wavelet transformation $W_{i}$ applied to time series $t_{i}$, where $i=1,2 \ldots \mathrm{N}$ (N- number of elements of the series), the local frequency wavelet spectrum is defined as the square of the absolute value of wavelet coefficients: $\left|w_{i}(t)\right|^{2}$.

The average of all local wavelet spectra gives global wavelet spectrum [16]:

(8) $W^{2}(t)=\frac{1}{N} \cdot \sum_{i=0}^{N-1}\left|w_{i}(t)\right|^{2}$.

In this study to determine the frequency spectrum is used continuous wavelet transformation, the basis of Morlet. For this purpose, a cubic spline interpolation based on the normal-to-normal intervals are applied. To obtain a constant sampling time, the non-uniform spacing in interval series are resampled at $4 \mathrm{~Hz}$. The most popular technique for timefrequency visualization in the analysis of nonstationary signals is spectrogram, which estimates the power spectral density (PSD) by applying the Periodogram to data.

\section{Results}

The described mathematical methods are implemented with a software program created by the author in the programming environment MATLAB. The developed software includes analysis of HRV in the time domain, frequency domain, nonlinear analysis, wavelet analysis and fractal analysis. The program allows for processing and analysis of the short-term 5 minute ECG signals and long-term 24hours Holter recordings.

The values of the investigated parameters in the time domain for patients with myocardial infarction, patients with syncope and healthy subjects are reported in table 3.

Table 4 shows the results of spectral methods in the frequency domain.

Table 5 shows the results of nonlinear methods (DFA method and method of Poincare) for the studied three groups of patients.

The obtained results show significant differences between the groups at:

Patients with myocardial infarction versus healthy controls:

- SDNN: $111.05 \pm 33.15$ versus $140.9 \pm 43.76$;

- SDANN: $98.63 \pm 46.58$ versus $143.68 \pm 38.48$;

- HRVTi: $7.1 \pm 1.85$ versus $10.22 \pm 3.92$;

- SD2: $150.05 \pm 75.38$ versus $197.28 \pm 61.12$;

- SD1 / SD2: $0.3 \pm 0.171$ versus $0.14 \pm 0.01$;

- Alpha1: $0.75 \pm 0.23$ versus $1.30 \pm 0.09$;

- Alpha2: $1.2 \pm 0.22$ versus $0.95 \pm 0.1$;

- LF: $537.87 \pm 391.42$ against $1173.35 \pm 486.23$;

- LF / HF: $1.11 \pm 0.83$ versus $2.45 \pm 1.16$.

Patients with syncope versus healthy controls:

- RMSSD 69.79-14.87 against 39.36 \pm 14.59 ;

- HRVTi: $7.21 \pm 2.38$ versus $10.22 \pm 3.92$;

- SD1: 49.35-31.73 against $27.84 \pm 10.33$;

- SD1 / SD2: $0.25 \pm 0.15$ versus $0.14 \pm 0.01$;

- HF 1297.63-1735.8 against 710.49-616.93.

Statistical analysis. The obtained results are presented as mean \pm standard deviation (SD). Statistical significance. In the scientific research, statisticians often choose a cutoff point under which a $p$-value must fall for a finding to be considered statistically significant. If the investigated p-value is less than or equal $0.05(5 \%)$, the result is deemed statistically significant - there is a significant relationship between the variables.

In this paper differences between the parameters of the groups are tested by the unpaired t-test. A $p$ parameter is determined by ANOVA analysis. Statistical analysis is performed using PSPP 0.10.1-g1082b8 application designed to analyze sampled data. 
Table 3. Time domain measures of HRV in different groups $(n=41)$

\begin{tabular}{|c|c|c|c|c|}
\hline \multirow{2}{*}{$\begin{array}{l}\text { Para- } \\
\text { meter }\end{array}$} & $\begin{array}{c}\text { Group } 1 \\
(n=19)\end{array}$ & $\begin{array}{c}\text { Group } 2 \\
(n=17)\end{array}$ & $\begin{array}{c}\text { Group } 3 \\
(n=5)\end{array}$ & \multirow{2}{*}{ p-value } \\
\hline & $\begin{array}{c}\text { mean } \\
\pm \text { sd }\end{array}$ & $\begin{array}{c}\text { Mean } \\
\pm \text { sd }\end{array}$ & $\begin{array}{c}\text { mean } \\
\pm \text { sd }\end{array}$ & \\
\hline $\begin{array}{c}\text { Mean } \\
\text { RR } \\
\text { (ms) }\end{array}$ & $\begin{array}{c}819.52 \pm \\
124.29\end{array}$ & $\begin{array}{c}878.89 \pm \\
149.04\end{array}$ & $\begin{array}{c}840.82 \pm \\
61.047\end{array}$ & 0.4 \\
\hline $\begin{array}{c}\text { Mean } \\
\text { HR } \\
\text { (bpm) }\end{array}$ & $\begin{array}{c}77.01 \pm \\
12.2\end{array}$ & $\begin{array}{c}72.77 \pm \\
11.97\end{array}$ & $\begin{array}{c}74.01 \pm \\
5.43\end{array}$ & 0.54 \\
\hline $\begin{array}{c}\text { SDNN } \\
(\mathrm{ms})\end{array}$ & $\begin{array}{c}111.05 \pm \\
33.15\end{array}$ & $\begin{array}{c}145.9 \pm \\
38.93\end{array}$ & $\begin{array}{c}140.9 \pm \\
43.76\end{array}$ & $<0.05$ \\
\hline $\begin{array}{l}\text { SDAN } \\
\text { N (ms) }\end{array}$ & $\begin{array}{c}98.63 \pm \\
46.58\end{array}$ & $\begin{array}{c}137.89 \pm \\
59.34\end{array}$ & $\begin{array}{c}143.68 \pm \\
38.48\end{array}$ & 0.053 \\
\hline $\begin{array}{c}\text { SDNN } \\
\text { index } \\
(\mathrm{ms})\end{array}$ & $\begin{array}{c}58.39 \pm \\
26.58\end{array}$ & $\begin{array}{c}69.31 \pm \\
34.86\end{array}$ & $\begin{array}{c}64.27 \pm \\
11.59\end{array}$ & 0.54 \\
\hline $\begin{array}{c}\text { RMSS } \\
\text { D } \\
(\mathrm{ms}) \\
\end{array}$ & $\begin{array}{c}57.98 \pm \\
29.58\end{array}$ & $\begin{array}{c}69.79 \pm \\
14.87\end{array}$ & $\begin{array}{c}39.36 \pm \\
14.59\end{array}$ & 0.2 \\
\hline HRVTi & $\begin{array}{l}7.1 \pm \\
1.85 \\
\end{array}$ & $7.21 \pm 2.38$ & $\begin{array}{c}10.22 \pm \\
3.92 \\
\end{array}$ & $<0.05$ \\
\hline $\begin{array}{c}\text { TINN } \\
(\mathrm{ms})\end{array}$ & $\begin{array}{c}407.49 \pm \\
157.69 \\
\end{array}$ & $\begin{array}{l}444.3 \pm \\
221.8 \\
\end{array}$ & $\begin{array}{c}540.78 \pm \\
138.18 \\
\end{array}$ & 0.366 \\
\hline
\end{tabular}

Group 1 - Patients with myocardial infarction Group 2 - Patients with syncope Group 3 - Healthy control group

For statistical analysis ANOVA method has been used The $p$-value of $<0.05$ is regarded as statistically significant

Table 4. Frequency domain measures of HRV in different groups $(n=41)$

\begin{tabular}{|c|c|c|c|c|}
\hline \multirow[t]{2}{*}{$\begin{array}{l}\text { Para- } \\
\text { meter }\end{array}$} & $\begin{array}{c}\text { Group 1 } \\
(n=19)\end{array}$ & $\begin{array}{c}\text { Group } 2 \\
(n=17)\end{array}$ & $\begin{array}{c}\text { Group } 3 \\
(n=5)\end{array}$ & \multirow[b]{2}{*}{ p-value } \\
\hline & $\begin{array}{c}\text { mean } \\
\pm \text { sd }\end{array}$ & $\begin{array}{c}\text { Mean } \\
\pm \text { sd }\end{array}$ & $\begin{array}{c}\text { mean } \\
\pm \text { sd }\end{array}$ & \\
\hline $\begin{array}{c}\mathbf{V L F} \\
\left(m s^{2}\right)\end{array}$ & $\begin{array}{c}10250.19 \\
\pm \\
12108.08\end{array}$ & $\begin{array}{c}17356.54 \\
\pm \\
18086.79\end{array}$ & $\begin{array}{c}10466.45 \pm \\
6079.982\end{array}$ & 0.32 \\
\hline $\begin{array}{c}\mathbf{L F} \\
\left(m s^{2}\right)\end{array}$ & $\begin{array}{c}537.87 \pm \\
391.42 \\
\end{array}$ & $\begin{array}{c}834.53 \pm \\
627.49\end{array}$ & $\begin{array}{c}1173.354 \pm \\
486.2256\end{array}$ & $<0.05$ \\
\hline $\begin{array}{c}\text { HF } \\
\left(m s^{2}\right)\end{array}$ & $\begin{array}{c}736.99 \pm \\
664.44\end{array}$ & $\begin{array}{c}1297.63 \pm \\
1735.8\end{array}$ & $\begin{array}{c}710.49 \pm \\
616.93\end{array}$ & 0.359 \\
\hline $\begin{array}{l}\text { LF/ } \\
\text { HF }\end{array}$ & $\begin{array}{c}1.11 \pm \\
0.83\end{array}$ & $\begin{array}{l}1.59 \pm \\
1.366\end{array}$ & $\begin{array}{c}2.45 \pm \\
1.16\end{array}$ & 0.05 \\
\hline
\end{tabular}

Group 1 - Patients with myocardial infarction Group 2 - Patients with syncope Group 3 - Healthy control group

For statistical analysis ANOVA method has been used The $p$-value of $<0.05$ is regarded as statistically significant
Table 5. Nonlinear parameters of HRV in different groups $(n=41)$

\begin{tabular}{|c|c|c|c|c|}
\hline \multirow[t]{2}{*}{$\begin{array}{l}\text { Para- } \\
\text { meter }\end{array}$} & $\begin{array}{c}\text { Group1 } \\
(n=19)\end{array}$ & $\begin{array}{c}\text { Group 2 } \\
(n=17)\end{array}$ & $\begin{array}{c}\text { Group } 3 \\
(n=5)\end{array}$ & \multirow{2}{*}{ p-value } \\
\hline & $\begin{array}{c}\text { mean } \\
\pm \text { sd }\end{array}$ & $\begin{array}{c}\text { mean } \\
\pm \text { sd }\end{array}$ & $\begin{array}{c}\text { mean } \\
\pm \text { sd }\end{array}$ & \\
\hline SD1 (ms) & $\begin{array}{c}40.99 \pm \\
20.92\end{array}$ & $\begin{array}{c}49.35 \pm \\
31.73\end{array}$ & $\begin{array}{c}27.84 \pm \\
10.33\end{array}$ & 0.239 \\
\hline SD2 (ms) & $\begin{array}{c}150.05 \pm \\
75.38\end{array}$ & $\begin{array}{c}198.54 \pm \\
21.6\end{array}$ & $\begin{array}{c}197.28 \pm \\
61.12\end{array}$ & $<0.05$ \\
\hline SD1/SD2 & $\begin{array}{c}0.3 \pm \\
0.171\end{array}$ & $\begin{array}{c}0.25 \pm \\
0.15\end{array}$ & $\begin{array}{c}0.14 \pm \\
0.01\end{array}$ & $<0.05$ \\
\hline alpha & $\begin{array}{c}1.115 \pm \\
0.185\end{array}$ & $\begin{array}{c}1.05 \pm \\
0.16\end{array}$ & $\begin{array}{c}1.01 \pm \\
0.07\end{array}$ & 0.067 \\
\hline alpha1 & $\begin{array}{c}0.75 \pm \\
0.23\end{array}$ & $\begin{array}{c}0.63 \pm \\
0.18\end{array}$ & $\begin{array}{c}1.30 \pm \\
0.09\end{array}$ & $<0.0001$ \\
\hline alpha2 & $\begin{array}{l}1.2 \pm \\
0.22\end{array}$ & $\begin{array}{c}1.14 \pm \\
0.16\end{array}$ & $\begin{array}{c}0.95 \pm \\
0.1\end{array}$ & $<0.05$ \\
\hline & $\begin{array}{l}1-\mathrm{Pa} \\
\text { Group } \\
\text { Group }\end{array}$ & $\begin{array}{l}\text { with m } \\
\text { atients } \\
\text { ealthy } \\
\text { ANOV }\end{array}$ & $\begin{array}{l}\text { dial infar } \\
\text { yncope } \\
1 \text { group }\end{array}$ & \\
\hline
\end{tabular}

For statistical analysis ANOVA method has been used

The $p$-value of $<0.05$ is regarded as statistically significant

\section{Conclusions from the analysis of Heart Rate Variability:}

- The values of temporal parameters SDNN, SDANN, HRTi, parameter SD2 of analysis of the Poincarŭ, alfa1 of the DFA analysis and low frequency parameters of frequency analysis of Heart Rate Variability, the relationship of simpatovagal balance $(\mathrm{LF} / \mathrm{HF})$ are significantly reduced in study patients with myocardial infarction and patients with syncope compared to healthy subjects.

- The values of the ratio SD1/SD2 analysis of the Poincare and alfa2 of the DFA analysis are significantly elevated in patients studied with cardiac disease compared to healthy subjects.

- Parameters SDNN, HRVTi, LF, LF/HF, SD2, SD1/SD2, alpha1, alpha2 are statistically significant because the $\mathrm{p}$ parameter determined by ANOVA analysis has values $<0.05$. The values of these parameters can be used to differentiate two groups of ill patients and healthy subjects.

The spectrogram is a useful tool for HRV analysis of ECG signals. The resulting graphical results (figure 1 to figure 3) show the distribution of frequencies (on the vertical axis) versus time (on the horizontal axis). The signal power is graphically depicted by using a color scale. Strong power is shown by dark red color and weak power by dark blue color.

The highest output frequency is indicated with dark red. Thick horizontal lines mark the boundaries of the investigated frequency bands.

The results are calculated for 5 minute segment of the data. VLF, LF and HF power are measured in absolute values of power $\left(m s^{2}\right)$. LF and HF can be also measured in percentage and normalized values (n.u.), which represent the relative value of each energetic component to the total 


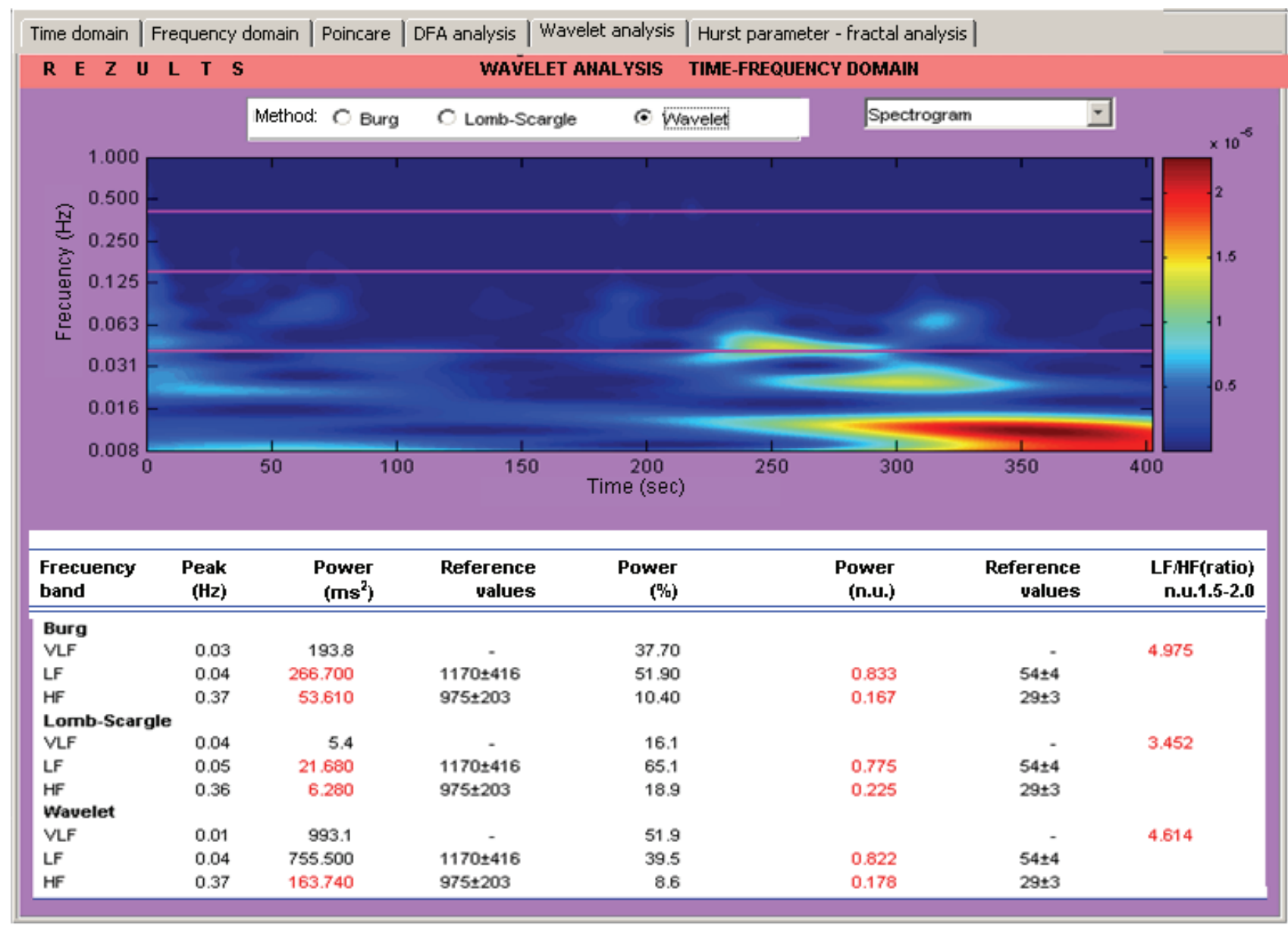

Figure 1. Results in time-frequency domain with wavelet analysis. The plot shows the spectrogram of RR intervals of a patient with cardiovascular disease

amount minus the value of the component VLF.

The table in figure 1 shows results of spectrum for VLF, LF and HF; the peak frequency for the three frequency ranges; simpatovagal index $(\mathrm{LF} / \mathrm{HF})$ and power reference values. The spectrogram depicted in figure 1 shows weak power in high frequency range and predominantly weak power in the low frequency range. The weak power in these two frequency ranges showed low Heart Rate Variability, which is an indicator of poor health status. These low values in the high frequency and low frequency range (shown in blue in the spectrogram) are confirmed by the resulting numerical values for the spectrum on the $\mathrm{HF}$ and LF areas, shown in the table in figure 1. The table numerical values for spectrum in absolute units and spectrum in normal units are colored red, because they are outside of their respective reference (normal) values. These reference values (presented in separate columns) are based on the Task Force, adopted in 1996 [2].

Figure 2 shows the wavelet spectrum of healthy subjects. The spectrogram shows high signal power (colored in yellow, orange and red) in the high frequency range and low frequency range. This demonstrated that the Heart Rate Variability is high and it is an indicator of very good general state of health. Figure $3 a$ shows a spectrogram of a patient diagnosed with ischemic heart disease, and figgure $3 b$ ) patient suffered a myocardial infarction. The spectrogram shows the low signal power (colored in blue) in the high frequency range and low-frequency range. This demonstrated that the Heart Rate Variability is low and it is an indicator of health problems.

The comparison between the spectrograms of healthy subjects and the spectrograms of cardiac disease subjects establishes different coloration in these spectrograms - a yellow-orange-red coloration in HF and LF in healthy subjects and blue coloring in unhealthy subjects.

Based on the graphical and numerical results, the following conclusions can be drawn:

1. There is observed a significant reduction in Heart Rate Variability after myocardial infarction.

2. There is an attenuation of frequencies in the high frequency range and in the low frequency range, in diseases such as ischemic heart disease.

3. Obtained (with wavelet transform) spectrograms may be used in the analysis of cardiac disease as an additional means.

4. The wavelet analysis is one of the best mathematical tools for graphic differentiation of healthy and unhealthy subjects. 


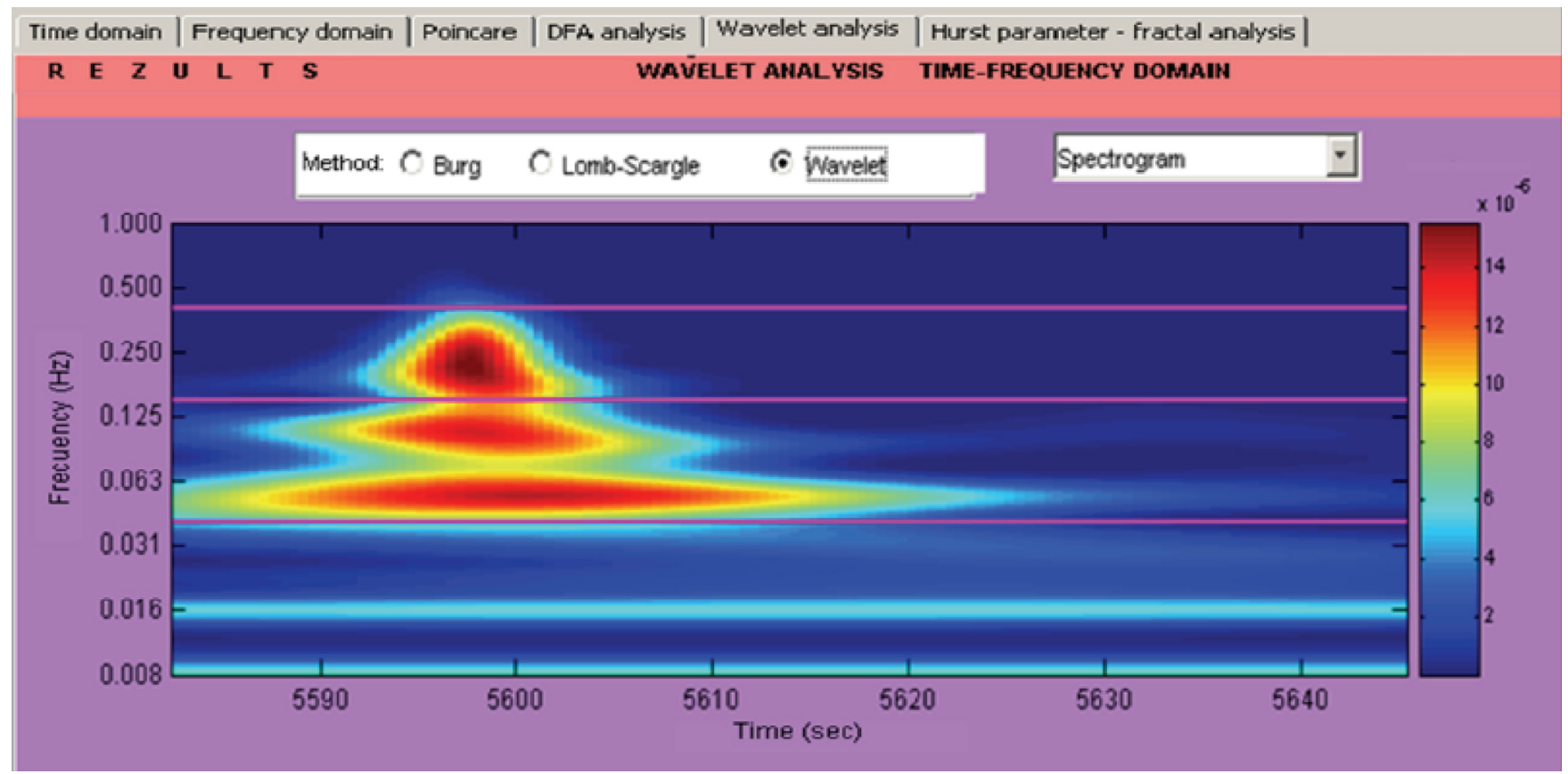

a)

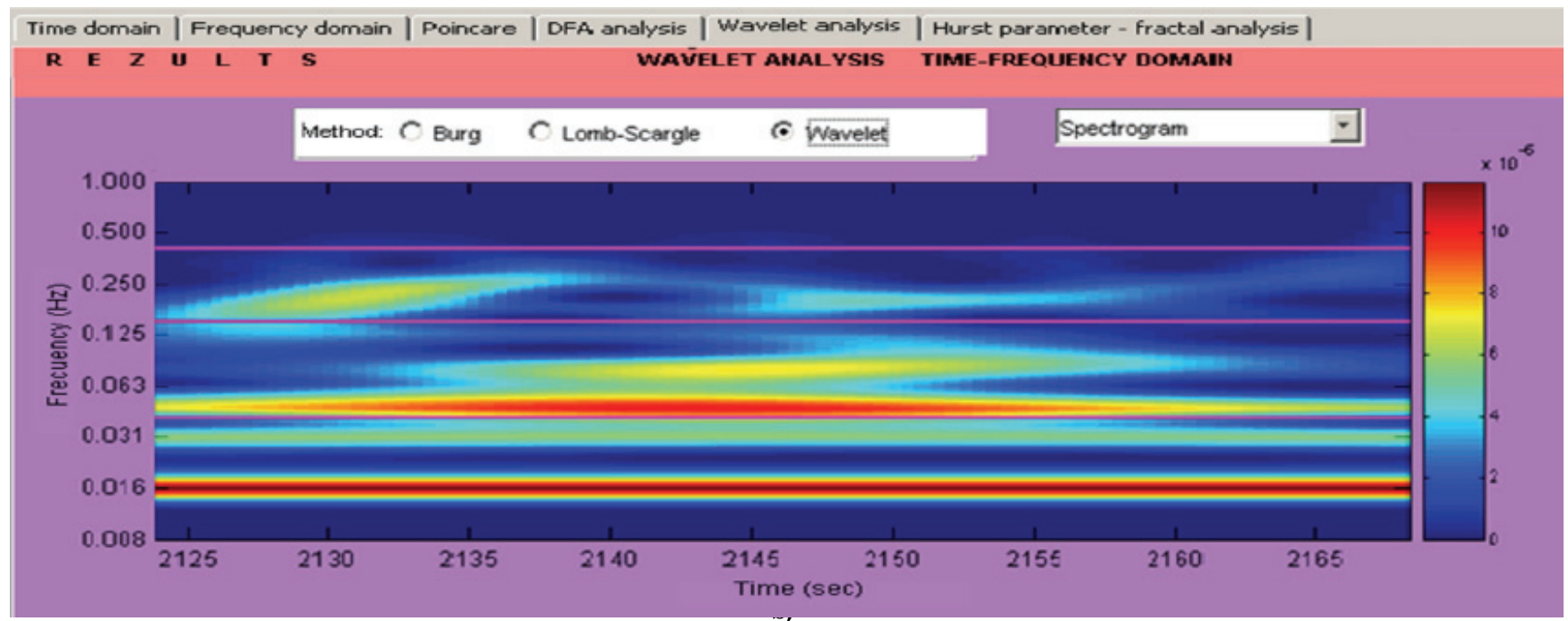

Figure 2. a), b.) Spectrograms (via wavelet analysis) of healthy subjects

\section{Conclusion}

HRV is a known risk factor for mortality in cardiovascular patients and healthy subjects. HRV analysis is an effective, powerful tool for measurement of cardiac autonomic activity. In this study are presented recent scientific researches and the results of application of linear, nonlinear and wavelet methods for cardiovascular patients. The used mathematical methods for HRV analysis are quantitative tools for assessing Heart Rate Variability.

The proposed graphical results of the cardiac data managed to give important information about the health condition of the subjects.

The values of investigated parameters are different for both investigated groups of patients (diagnosed with myocardial infarction and diagnosed with syncope) and healthy subjects. The proposed mathematical methods are quite useful for diagnosing the cardiovascular diseases. The developed application software for the illustrated above methods, designed for mathematical analysis of ECG signals, could be utilized by physicians as additional mathematical tool for presentation of pathological status of patients. 


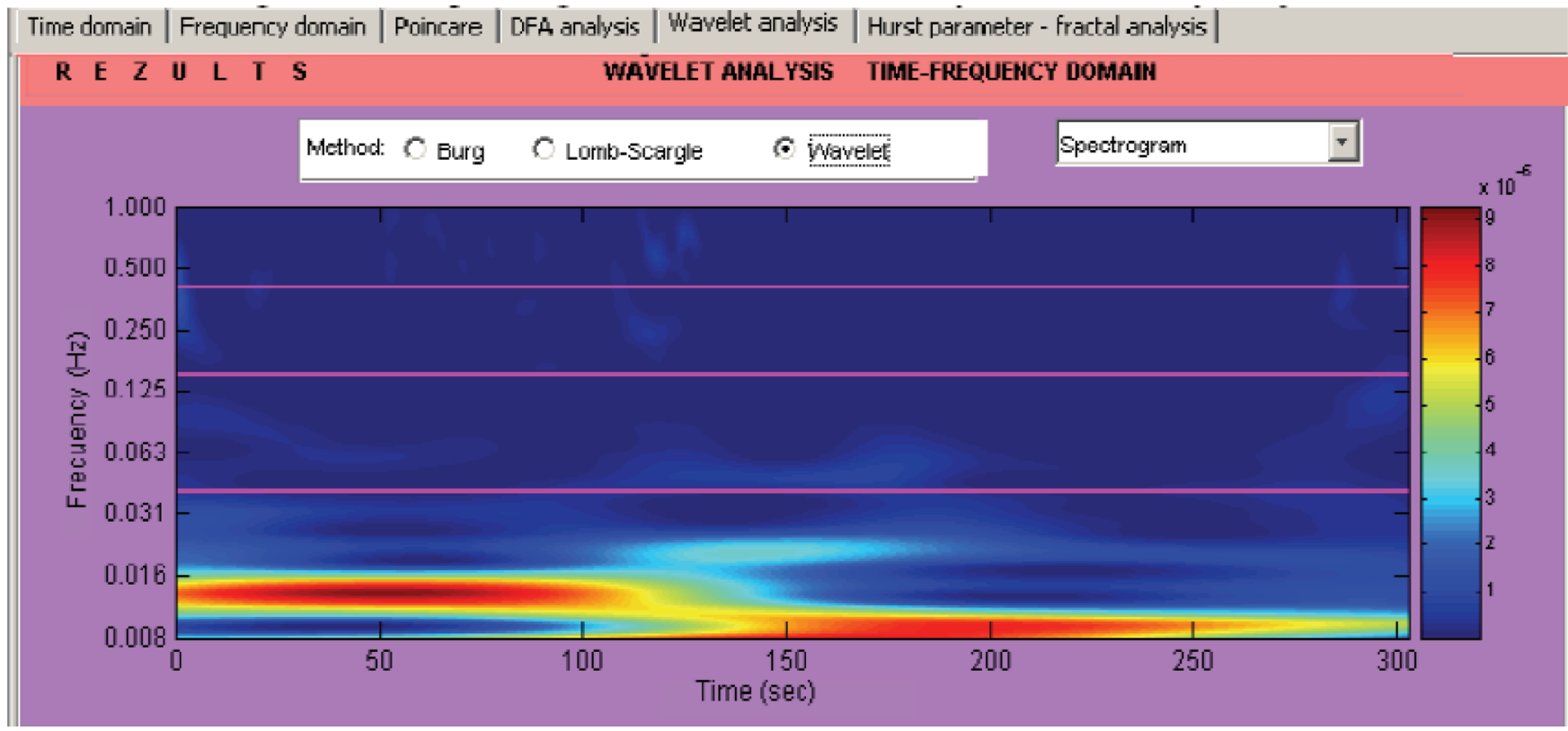

a) Spectrogram of a patient with ischemic heart disease

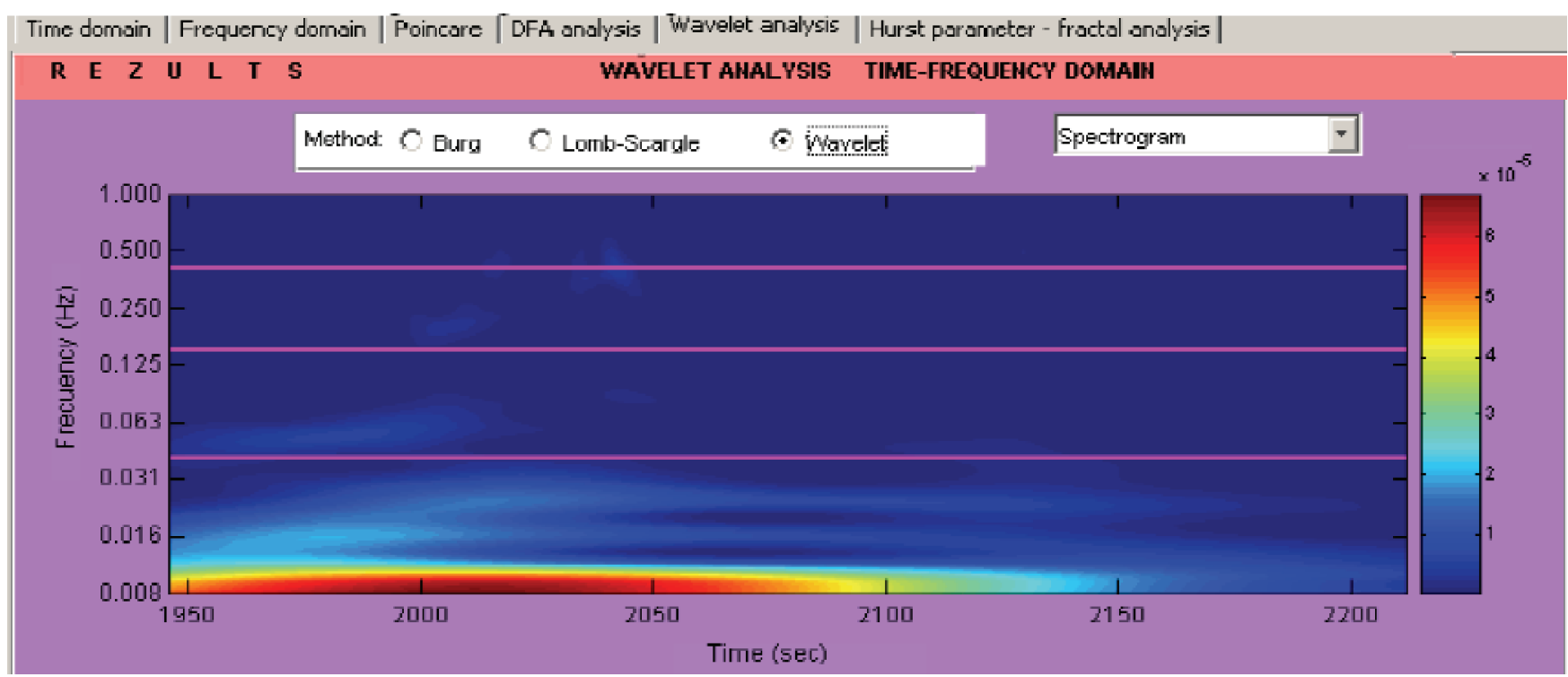

b) Spectrogram of patient with myocardial infarction

Figure 3. a), b) Spectrograms (via wavelet analysis) of patients with cardiovascular diseases

The applied wavelet analysis of RR intervals data are quite suitable tool for the evaluation of Heart Rate Variability and can be successfully used as an additional tool for graphically differentiation of healthy subjects and patients with cardiovascular disease.

\section{References}

1. Marchev, S. Heart Rate Variability - Measurement Standards. Cardio - Vascular Diseases. 1998, 1, 28-35 (in Bulgarian).
2. Task Force of the European Society of Cardiology and the North American Society of Pacing and Electrophysiology. Heart Rate Variability: Standards of Measurement, Physiological Interpretation, and Clinical Use. - Circulation, 93, 1996, 1043-1065.

3. Acharya, U. R., K. P. Joseph, N. Kannathal, C. M. Lim, J. S. Suri. Heart Rate Variability: a Review. - Med. Bio. Eng. Comput, 44, 2006, 1031-1051.

4. Addison, P. Wavelet transforms and the ECG: a review, Physiol.Meas., 2005, No. 26, R155-R199.

5. Clifford, G., F. Azuaje, P. McSharry, Editors. Advanced Methods and Tools for ECG Data Analysis. Artech House, Inc., Boston/ London, 2006. 
6. Clifford, G. Signal Processing Methods for HRV. Michaelmas Term, 2002.

7. Ernst, G. Heart Rate Variability. Springer-Verlag London, 2014. 8. Kumar, D. M., S. C. Prasannakumar, B. G. Sudarshan, D. Jayadevappa. Heart Rate Variability Analysis: A Review. International Journal of Advanced Technology in Engineering and Science, 1, June 2013, Issue 6, 9-24.

9. Acharya, U. R., J. S. Suri, J. A. E. Spaan, S. M. Krishnan. Advances in Cardiac Signal Processing. Springer-Verlag Berlin Heidelberg 2007 Torrence C., G. P. Compo. A Practical Guide to Wavelet Analysis. - Bulletin of the American Meteorological Society, 1998, No. 79, 61-78.

10. Mali, B., S. Zulj, R. Magjarevic, D. Miklavcic, T. Jarm. Matlabbased tool for ECG and HRV analysis. - Biomedical Signal Processing and Control, 10, 2014, 108-116.

11. Akar, S. A., S. Kara, F. Latifoglu, V. Bilgic. Spectral Analysis of Photoplethysmographic Signals: The Importance of Preprocessing. - Biomedical Signal Processing and Control, 8, 2013, 1,16-22.

\section{Manuscript received on 19.12 .2016}

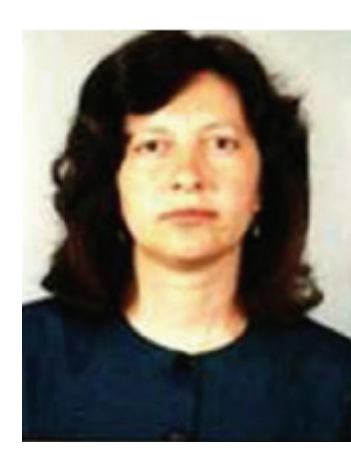

Galya Georgieva-Tsaneva received the M.Sc. degree in Electronical Engineering from the Technical University of Varna, Bulgaria in 1989 and Ph.D. degree on Components and Devices of Automation and Computing Equipment from the Institute of Systems Engineering and Robotics (ISER) of the Bulgarian Academy of Sciences (BAS) in 2016. Up to date she is an Assistant Professor at the ISER of BAS, Sofia, Bulgaria. Her scientific research interests include medical information system, investigation of Heart Rate Variability of ECG data, wavelet and fractal analysis, computer networks and communications, coding and compression of information, fractal modeling and teletraffic engineering.
12. Proakis, J. G., D. G. Manolakis. Digital Signal Processing. Prentice-Hall Inc., New Jersey, 1996 (Chapter 12).

13. Merati, G., M. D. Rienzo, G. Parati, A. Veicsteinas, P. Castiglioni. Assessment of the Autonomic Control of Heart Rate Variability in Healthy and Spinal-cord Injured Subjects: Contribution of Different Complexity-based Estimators. - IEEE Transactions on Biomedical Engineering, 53, 2006, No. 1, 43-52.

14. Leite, F. S., A. da Rocha, J. Carvalho. MATLAB Software for Detrended Fluctuation Analysis of Heart Rate Variability. Biosignals 2010, International Conference on Bio-inspired Systems and Signal Processing, 2010, 225-229.

15. Piskorski, J., P. Guzik. Geometry of the Poincare Plot of RR Intervals and its Asymmetry in Healthy Adults. - Physiol. Meas, 28, 2007, 287-300.

16. Torrence, C., G. P. Compo. A Practical Guide to Wavelet Analysis. - Bulletin of the American Meteorological Society, 1998, No. 79, 61-78.

Contacts:

Institute of Systems Engineering and Robotics Bulgarian Academy of Sciences Acad. G.Bonchev Str., Bl. 2, P.O. Box 79 1112 Sofia, Bulgaria tel.+359878111283 e-mail: galicaneva@abv.bg 


\section{Call for papers}

You are invited to submit a research paper for publication in ITC Journal

\section{Journal Information Technologies and Control}

Print ISSN 1312-2622

On-line ISSN 2367-5357

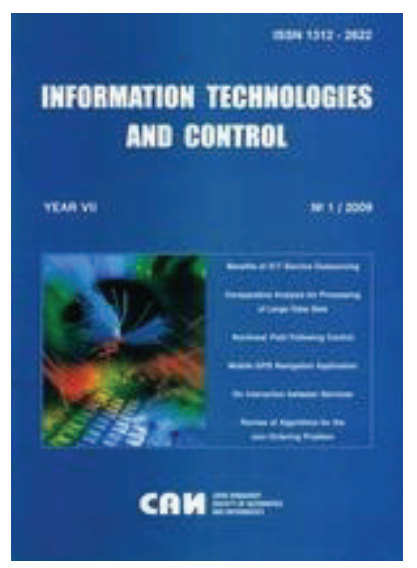

The Information Technologies and Control is an Online Open Access Peer-Reviewed International Journal started in 2002. It publishes original contributions including theoretical as well as application papers in the areas of information processing and control engineering. Topics include, but are not limited to: adaptive control, artificial intelligence, biological and medical systems, computer communication technologies, control of manufacturing systems, control of process systems, discrete event systems, high performance computing, identification and filtering, intelligent systems, multi-agent systems, network control systems, operations research, optimal control, pattern recognition, robot control, robust control, signal and image processing, scientific computations, software technologies, information technologies and control in education. Survey articles will also be considered.

The journal publishes 4 regular issues per annum and/or some additional special thematic issues with selection of extended papers from international scientific events.

The journal "Information Technologies and Control" is abstracted/indexed in 17 data bases: Baidu Scholar, Celdes, CNKI Scholar (China National Knowledge Infrastructure), CNPIEC, EBSCO Discovery Service, Genamics JournalSeek, Google Scholar, J-Gate, JournalTOCs, Naviga (Softweco), Primo Central (ExLibris), ReadCube, ResearchGate, Summon (Serials Solutions/ProQuest), TDOne (TDNet), TEMA Technik und Management, WorldCat (OCLC).

Each paper obtains DOI.

For more Information and Author Guidelines visit www.degruyter.com/view/j/itc.

For author's convenience, we recommend the following steps.

1. Submit article to: sai.bg.office@gmail.com .

2. Peer review process is now accelerated to save authors 'valuable time. Authors will get their Acceptance/Rejection Notification within 20 days of submitting paper.

3. All the accepted papers will be open accessible with full PDF download.

4. Corresponding author of the paper will get the soft copy of the journal.

5. Each accepted paper will be charged by publication fee of 70 Euro. 